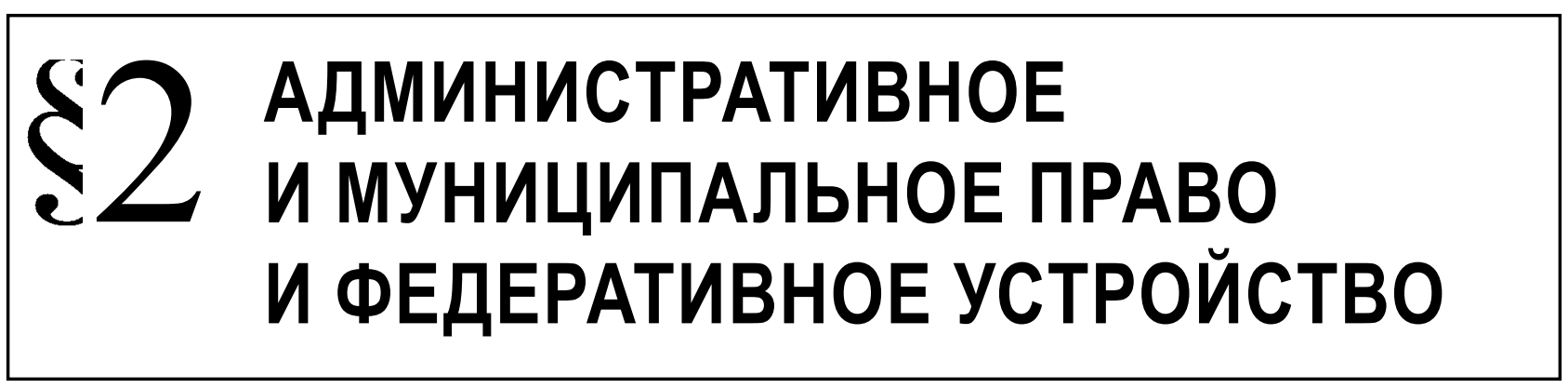

Крылов О.М.

\title{
ДЕНЕЖНОЕ ОБРАЩЕНИЕ КАК ОБЪЕКТ ФИНАНСОВОЙ БЕЗОПАСНОСТИ ГОСУДАРСТВА
}

\begin{abstract}
Аннотация: Предметом исследования выступают финансово-правовые нормы, регулирующие общественные отношения, складывающиеся преимущественно в процессе организации финансовой безопасности государства. Среди разнообразных объектов финансовой безопасности государства выделяется область денежнокредитных отношений, защищенность которой в настоящий момент приобретает особую актуальность. Современная организация денежного обращения государства невозможна без использования инструментов и механизмов, как финансовой безопасности государства, так и его национальной безопасности, поскольку они служат гарантией обеспечения конституционных прав, свобод, достойного качества и уровня жизни граждан, суверенитета, территориальной целостности и устойчивого развития государства, его обороны и безопасности. Методологической основой служит диалектический метод научного познания социальных, экономических и правовых явлений в их взаимосвязи и взаимообусловленности. Достоверность и обоснованность результатов достигается за счет комплексного применения системно-структурного, сравнительноправового, формально-юридического и логико-теоретических методов, а также метода описания понятий, анализа, синтеза, обобщения и иных методов. В результате проведенного исследования автор приходит к выводу, что безопасность денежного обращения государства предстает элементом национальной безопасности. Это такое состояние защищенности государства от внутренних или внешних угроз, которое позволяет в процессе организации им денежного обращения обеспечить устойчивое и прогрессивное развитие его денежной системы, что, в свою очередь, обеспечивает конституционные права, свободы, достойные качество и уровень жизни граждан, суверенитет, территориальную целостность и устойчивое развитие Российской Федерации, оборону и безопасность государства. Поскольку в качестве объекта финансовой безопасности государства не представляется возможным рассматривать все денежное обращение, автор предлагает использовать категорию "безопасность денежного обращения государства» наряду с категорией «финансовая безопасность государства».
\end{abstract}

Ключевые слова: деньги, безопасность, финансы, обращение, государство, система, функция, деятельность, эмиссия, экономика.

Review: The subject of the study contains the financial and legal rules regulating the public relations which develop mainly during the organization of the state financial security. Among the various objects of financial security of the state the area of monetary relations can be outlined, and its security gains a particular importance at the present day. The current organization of the state monetary circulation is impossible without the mechanisms such as the state financial security and national security because they serve as a guarantee of the constitutional rights, freedoms, adequate quality of life and living standards of citizens, sovereignty, territorial integrity and sustainable development of the state and its defense and security.The methodology is based on the dialectical method of scientific cognition of social, economic and legal phenomena in their interrelationship and interdependence. Reliability and validity of the results are achieved through the application of the integrated system-structural, comparative legal, formal legal and logical-theoretical methods, as well as the method of describing the concepts, analysis, synthesis, and other methods. The author concludes that the safety of the state is a monetary element of the national security. This is the condition of safety of the state from 
the internal or external threats which allows provision of sustainable and progressive development of its financial system in the process of money circulation, which in turn provides the constitutional rights, freedoms, adequate quality of life and living standards of citizens, sovereignty, territorial integrity and sustainable development of the Russian Federation, the defense and security of the state. Since it is impossible to consider money circulation in general as an object of the financial security of the state, the author proposes to use the category of "monetary security of the state" along with the category of "financial security of the state."

Keywords: emission, activity, function, system, state, circulation, finance, security, money, economy.

$\mathrm{K}$ атегория «финансовая безопасность» используется в настоящий момент в нормативных правовых актах без раскрытия ее содержания [1], что явилось основанием для дискуссий в правовой науке по этому поводу [2-9].

Автор, руководствуясь тем, что финансовая безопасность представляет собой элемент национальной безопасности, под финансовой безопасностью государства понимает такое состояние защищенности государства от внутренних и внешних угроз, которое позволяет в процессе осуществления им финансовой деятельности обеспечить устойчивое развитие его финансовой системы.

Отдельными учеными (Долматова Н. Г., Кондрат Е. Н.) делается вывод о том, что финансовая безопасность государства включает в себя состояние защищенности от различных угроз в области бюджетной деятельности, налогообложения, a также валютных отношений и денежно-кредитной системы.

Отметим, что категория «денежная система» в настоящий момент не имеет законодательного закрепления. Не раскрывал содержание этой категории и закон Российской Федерации «О денежной системе Российской Федерации», который лишь устанавливал элементы денежной системы Российской Федерации: официальная денежная единица, эмиссия наличных денег, организация и регулирование денежного обращения [10].

В правовой науке доминирует представление о денежной системе как исторически сложившейся и закрепленной форме организации денежного обращения в государстве [11-13]. В рассматриваемом смысле денежная система Российской Федерации является результатом государственной деятельности, имеющей целью обеспечить совместную деятельность (как экономическую, так и иную деятельность) людей с помощью упорядоченных денежных отношений $[14$, с. 20]. Иными словами денежная система является результатом государственной деятельности, организующей денежное обращение.

Эта деятельность является также и финансовой деятельностью, если она направлена на со- вершение организационных и иных действий органов государства, как правило, в правовой форме, в процессе распределения внутреннего валового продукта и части национального дохода общества путем образования, распределения (перераспределения) и использования различных фондов денежных средств, как централизованных, так и децентрализованных, необходимых для обеспечения финансовыми ресурсами функционирования органов государства всех трех ветвей власти, осуществления мероприятий по внутренней безопасности и обороне страны, для выполнения национальных программ социально-экономического и культурного развития и удовлетворения иных потребителей общества [15, с. 47].

Организация денежных потоков, с помощью которых обеспечивается создание и использование денежных ресурсов общества, осуществляется в процессе финансовой деятельности государства, которая по своему содержанию предстает организацией денежного обращения в сфере публичных финансов. Вследствие осуществления финансовой деятельности государством происходит процесс непрерывного движения денег в сфере публичных финансов, а ее результатом является образование централизованных и децентрализованных фондов, используемых на финансирование потребностей общества [16, с. 4].

Организация денежного обращения может и не являться финансовой деятельностью, поскольку упорядоченные денежные отношения обеспечивают как создание и использование денежных ресурсов общества, так и опосредование эквивалентно-возмездных общественных отношений $[17$, c.12].

В современной науке финансового права некоторыми учеными организация денежного обращения рассматривается в качестве функции финансовой деятельности государства. Такой позиции, в частности, придерживается А. И. Худяков, Е. М. Ашмарина $[18,19]$. Большинство же ученых, тем не менее, организацию денежного обращения не относят к функциям финансовой деятельности государства [20-26]. Не смотря на это, отдельны- 
ми авторами до сих пор предпринимаются попытки обосновать обратное. В частности, Арзуманова Л. Л. в качестве функции финансовой деятельности государства вообще определяет элемент организации денежного обращения - эмиссию наличных денег. Так, эмиссия - это урегулированное нормами права направление финансовой деятельности государства, осуществляемое эмиссионным банком (Центральным банком Российской Федерации), и заключающееся в установлении порядка выпуска денег, приводящего к изменению денежной массы в обращении, и изъятию из обращения денежных средств [27 с. 8]. В качестве обоснования такого вывода автор называет признаки эмиссии, свидетельствующие, по его мнению, об этом: первичность по отношению к другим видам финансовой деятельности, проводится в процессе планомерного выпуска денежных средств в оборот, осуществляемого на основе прогнозного планирования Банка России, базируется на нормативно-правовых актах, является предметом исключительного ведения Российской Федерации, основным участником этого направления деятельности является государство, выступающее в лице Центрального банка Российской Федерации. Однако все эти признаки в равной степени свидетельствуют и о том, что эмиссия - разновидность иной, нефинансовой деятельности государства (например, деятельности по организации гражданского оборота).

Действительно, в Российской Федерации эмиссия наличных денег предстает в качестве совокупности следующих операций: прогнозирование, организация производства, в том числе размещение заказа на изготовление банкнот и монеты Банка России у организации, изготавливающей банкноты и монету Банка России, перевозка банкнот и монеты Банка России, хранение банкнот и монеты Банка России, создание резервных фондов банкнот и монеты Банка России, их выпуск в обращение [28, ст. 34].

Финансово-правовое регулирование общественных отношений, возникающих при осуществлении перечисленных операций, представляется возможным лишь в случае, если указанные операции составляют динамичную сторону финансовой деятельности государства. Этот вывод со всей очевидностью следует из такой особенности финансовых правоотношений, как их возникновение в процессе осуществления финансовой деятельности государства и муниципальных образований.

Общественные же отношения, складывающиеся в процессе эмиссии наличных денег, возника- ют в результате совершения операций, не являющимися операциями финансовой деятельности государства и муниципальных образований, и не регулируются нормами финансового права, а регулируются, преимущественно, нормами административного и гражданского права. Например, операция по выпуску в обращение бумажных банкнот и металлической монеты может быть осуществлена после их перевода из резервных фондов в оборотные кассы расчетно-кассовых центров Банка России по приему и выдаче наличных денег.

Посредством оборотных касс осуществляется выдача кредитным организациям наличных денег с последующим списанием соответствующих денежных сумм с их счетов, либо принимаются от кредитных организаций наличные деньги с последующим зачислением на их счета. С правовой позиции выпуск наличных денег в обращение путем передачи бумажных банкнот и металлической монеты Банка России кредитным организациям, по своей сути, представляет собой замену безналичного денежного обязательства на наличные деньги. Такая операция не направлена на совершение действий по образованию, распределению и использованию централизованных и децентрализованных денежных фондов государства и муниципальных образований. Следовательно, не осуществляется и финансово-правовое регулирование возникающих общественных отношений. По своей правовой природе эти общественные отношения являются гражданскими отношениями.

Вообще следует констатировать, что в современной финансово-правовой науке присутствует определенная «размытость» понимания соотношения дефиниций «функция государства», «финансовая деятельность государства», «организация денежного обращения». Например, Э. Д. Соколова приходит к выводу о том, что она, по своей сути, является самостоятельным направлением деятельности государства (его функцией), обусловленной наличием товарно-денежного обращения и необходимостью создания различных фондов денежных средств, без которых функционирование государства в обществе с товарно-денежным обращением немыслимо.

Вместе с тем, в теории права система функций государства чаще всего рассматривается посредством выделения определенных классификационных критериев. Одним из таких критериев является социальная значимость, на основе которой функции государства подразделяются на основные и производные (неосновные) [29-31]. К основным 
функциям государства относятся наиболее важные, приоритетные направления государственной деятельности в определенный исторический период. Производные функции определяются основными, вытекают из них и, по сути, представляют своеобразные подфункции, которые воплощают специфически особенное в рамках конкретного направления деятельности и в воздействии на общественные отношения.

Экономическая функция является общепризнанной основной функцией, содержанием которой является воздействие государства на экономические процессы в обществе. На экономические процессы воздействует также как финансовая деятельность государства, так и организация денежного обращения. Так, финансовая деятельность государства определена экономикой, а финансовые отношения являются разновидностью экономических отношений. Поскольку финансовое правоотношение имеет властно-имущественный характер и выражает публичные интересы, в самой сущности финансового правоотношения заложены противоречия между экономическим содержанием и политической формой, между публичными и индивидуальными интересами [32, с. 94].

Это свидетельствует о том, что финансовая деятельность государства осуществляет воздействие не только на экономику, но и на социальные общественные процессы (и не только), выходящие за рамки содержания экономической функции государства. Следовательно, финансовая деятельность государства не может быть подфункцией экономической функции государства.

Вместе с тем, содержание категории «финансовая деятельность государства» по отношению к категории «организации денежного обращения» более узкое, поскольку финансовая деятельность государства предстает организацией денежного обращения в сфере публичных финансов. Государство же организует денежный оборот не только в сфере публичных финансов, осуществляя при этом иную (не финансовую) деятельность. Таким образом, организация денежного обращения государством упорядочивает систему денежных отношений, посредством которых происходит планомерное распределение и перераспределение и обмен общественного продукта, которые опосредуются как финансовыми, так и иными (нефинансовыми) отношениями.

Являясь по отношению к финансовой деятельности государства более широким понятием, организация денежного обращения как государ- ственная деятельность осуществляет воздействие как на экономику, так и на разнообразные общественные процессы, выходящие за рамки экономической функции государства [33, с. 6].

Следовательно, организация денежного обращения выходит за рамки содержания экономической функции государства и является более широким понятием по отношению к финансовой деятельности государства. С этих позиций она предстает основной функцией государства.

Общеизвестно, что функции государства обладают существенными признаками, определяющими предмет, цель, способы и формы. Так, предметом организации денежного обращения являются денежные отношения, возникающие в результате всех типов совместной деятельности людей (экономической и иной деятельности) в различных сферах общественных отношений. Целью организации денежного обращения является обеспечение этой совместной деятельности с помощью упорядоченных денежных отношений. А основными способами организации денежного обращения являются убеждение и принуждение, характеризующиеся особенностями, обусловленные отношениями, на которые осуществляется целенаправленное государственное воздействие. Кроме того, имеются особенности правовых форм (прежде всего, правотворческой и правоприменительной деятельности) организации денежного обращения, характеризующие ее как самостоятельную функцию государства.

Организация денежного обращения, как деятельность государства, затрагивает все важнейшие сферы общества: труд, гражданский оборот, социальное обеспечение, финансы и т.д. Затрагивая перечисленные сферы общества, она способствует осуществлению разнообразных общественных процессов, обеспечивая тем самым существование общества как суверенного самостоятельного организма. Организуя денежное обращение, государство направляет свою деятельность на выполнение крупных целей и задач современного этапа своего развития: формирует элемент образа жизни человека, устанавливает средства мотивации трудовой деятельности, а также обеспечивает осуществление трудовой деятельности человека, финансовой и социальной деятельности государства и муниципальных образований, гражданского оборота в обществе и т.д.

В свою очередь финансовая деятельность государства в большинстве перечисленных сфер общества существенно ограничена, что предопре- 
деляет ее производный характер и проявление не столь явно выраженной связи между сущностью государства и его социальным назначением, как в случае с организацией денежного обращения. Цели и задачи финансовой деятельности государства менее масштабны и являются частью целей и задач организации денежного обращения.

Таким образом, организация денежного обращения наряду с экономической функцией предстает в качестве основной функции государства, тогда как финансовая деятельность государства - подфункцией организации денежного обращения.

Руководствуясь приведенным пониманием рассматриваемых категорий, следует сделать вывод, что денежное обращение является объектом финансовой безопасности лишь в части сферы публичных финансов. Такой вывод следует из того, что финансовая безопасность предполагает обеспечение устойчивого развития финансовой системы государства в процессе осуществления им финансовой деятельности, а финансовая деятельность ограничивается вопросами организации денежного обращения исключительно в сфере публичных финансов.

Вместе с тем, следует учесть, что хотя внутри денежного оборота складываются различные денежные потоки, часть из которых обеспечивает создание и использование денежных ресурсов общества, а другая часть опосредствует эквивалентно-возмездные общественные отношения, сам денежный оборот является единым. А это означает невозможность в полной мере обеспечить устойчивое развитие финансовой системы государства в процессе осуществления им финансовой деятельности без состояния защищенности всего денежного обращения.

Организация денежного обращения осуществляется не только как финансовая деятельность и не ограничивается обеспечением развития финансовой системы государства, поэтому представляется невозможным в качестве объекта финансовой безопасности государства рассматривать все денежное обращение. Но поскольку необходимость защищенности денежного обращения от внутренних и внешних угроз не вызывает сомнения, автор предлагает ввести категорию «безопасность де- нежного обращения государства», используемую наряду с категорией «финансовая безопасность государства».

Следует отметить, что, являясь функцией государства, организация денежного обращения в ряде случаев осуществляется с помощью денежных суррогатов, например, частных денег (bitcoin и т.д.). Эмиссия денежных суррогатов принимает значительные размеры, когда в экономике происходит глобальная трансформация, а государство не может проводить адекватную ей денежную политику или просто игнорирует происходящие в экономике изменения. Раз и навсегда запретить эмиссию частных обязательств в законодательном порядке практически невозможно. При самом суровом и регламентированном законодательстве всегда найдется лазейка для их эмиссии [34, с.31].

Учитывая это обстоятельство, а также обеспечительный характер цели организации денежного обращения по отношению к любой деятельности (экономической и иной деятельности) людей в различных сферах общественных отношений, представляется, что безопасность денежного обращения государства является элементом не государственной, а национальной безопасности. В указанном качестве безопасность денежного обращения государства обеспечивает конституционные права, свободы, достойные качество и уровень жизни граждан, суверенитет, территориальную целостность и устойчивое развитие Российской Федерации, оборону и безопасность государства [35] (указ Президента Российской Федерации от 12 мая 2009 № 537 «О Стратегии национальной безопасности Российской Федерации до 2020 года»).

Таким образом, безопасность денежного обращения государства как элемент национальной безопасности есть такое состояние защищенности государства от внутренних или внешних угроз, которое позволяет в процессе организации им денежного обращения обеспечить устойчивое и прогрессивное развитие его денежной системы, что, в свою очередь, обеспечивает конституционные права, свободы, достойные качество и уровень жизни граждан, суверенитет, территориальную целостность и устойчивое развитие Российской Федерации, оборону и безопасность государства.

\section{Библиография:}

1. Об утверждении Концепции развития рынка ценных бумаг в Российской Федерации: Указ Президента Российской Федерации от 01 июля 1996 г. № 1008 (в ред. от 16 октября 2000 г. № 1756) // Российская газета. 1996. № 125. 
2. Чапчиков С. Ю. Конституционные гарантии обеспечения безопасности общества и государства // Конституционное и муниципальное право. 2009. № 17. С. 11 - 14.

3. Клещенко Ю. Г., Савченко М. М. Финансовый контроль как один из факторов обеспечения финансовой безопасности // Финансовое право. 2009. № 5. С. 12 - 15.

4. Петросян О. Ш. Финансовая безопасность Российского государства в контексте национальной безопасности // Государственная власть и местное самоуправление. 2011. № 2. С. 32 - 34.

5. Нудель С. Л. Финансовая безопасность и основные направления ее обеспечения // Финансовое право. 2011 . № 8. С. $14-16$.

6. Беликов Е. Г. Социальные аспекты функционирования национальной платежной системы // Банковское право. 2014. № 4. С. 19 - 23.

7. Кондрат Е. Н. Международная финансовая безопасность: современное состояние и роль финансового контроля в ее обеспечении // Юридический мир. 2011. № 12. С. 32 - 34.

8. Моргун О. В., Щедрин Н. В. Основания и пределы мер финансовой безопасности // Актуальные проблемы российского права. 2013. №

9. . 1165 - 1173. 9.Долматова Н. Г. Понятие финансовой безопасности государства как объекта правового регулирования // Финансовое право. 2014. № 5. С. 33-37.

10. О денежной системе Российской Федерации: Закон Российской Федерации от 25 сентября 1992 г. № $3557-1$ (утратил силу в связи с принятием Федерального закона от 26 апреля 1995 № 65-ФЗ) // Российская газета. 1992. № 230.

11. Бельский К. С. К вопросу о понятии денежной системы Российской Федерации // Финансовое право. 2005. № 8. С. $3-6$

12. Саттарова Н. А. Деньги как объект гражданских прав. - Казань: Таглимат. 2006. 86 с.

13. Кучеров И. И. Законное платежное средство как категория финансового права // Журнал российского права. 2014. № 8. С. 38 - 47.

14. Крылов О. М. Правовое регулирование денежного обращения в Российской Федерации: монография /отв. ред. С. В. Запольский. - М.: КОНТРАКТ, 2014. 104 с.

15. Соколова Э. Д. Правовое регулирование финансовой деятельности государства и муниципальных образований. М.: Юриспруденция, 2009. 264 с.

16. Крылов О. М. Дискуссионные вопросы финансово-правового регулирования денежного обращения в Российской Федерации // Финансовое право. 2014. № 8. С.3 - 10.

17. Запольский С. В. Теория финансового права: Научные очерки. - М.: ГОУ ВПО «Российская академия правосудия», 2010. 371 с

18. Худяков А. И. Финансовое право Республики Казахстан. Общая часть. Алматы: ТОО «Баспа», 2001. 272 с.

19. Ашмарина Е. М. Некоторые аспекты расширения предмета финансового права в Российской Федерации: проблемы и перспективы: монография. М.: Полиграф ОПТ, 2004. 253 с.

20. Гурвич М.А. Советское финансовое право. М.: Госюриздат, 1952. 324 с.

21. Ровинский Е. А. Основные вопросы теории советского финансового права. М.: Госюриздат, 1960. 193 с.

22. Кучерявенко Н. П. К вопросу о согласовании норм, регулирующих финансовую деятельность // Финансовое право. 2004. № 1. С. 10 - 13.

23. Финансовое право: учебное пособие / отв. ред. И. В. Рукавишникова. М.: Норма, 2007. 512 с.

24. Финансовое право: Учебник / отв. ред. Н. И. Химичева. М.: Норма, 2011. 768 с.

25. Финансовое право: учебник / под ред. Е. Ю. Грачевой. М., 2012. 789 с.

26. Крохина Ю. А. Финансовое право России: учебник. М.: Норма, 2011. 720 с.

27. Арзуманова Л. Л. Право денежного обращения как подотрасль финансового права Российской Федерации: автореф. дис....на соиск. учен. ст. д-ра юрид. наук. Специальность 12.00.04-финансовое право, налоговое право, бюджетное право / Л. Л. Арзуманова ; науч. конс. Е. Ю. Грачева.-М., 2014.-44 с.

28. О Центральном банке Российской Федерации (Банке России): Федеральный закон от 10 июля 2002 г. № $86-Ф 3$ (в ред. от 29 декабря 2014 г. № 484-ФЗ) // Российская газета. 2002. № 127.

29. Теория государства и права: учебник / под ред. Р. А. Ромашова. СПб.: Издательство Р. Асланова «Юридический центр Пресс», 2005. 630 с.

30. Теория государства и права: Курс лекций / Под ред. Н. И. Матузова и А. В. Малько. - М.: Юристъ, 2006.776 с.

31. Теория государства и права: учебник / под ред. В.К. Бабаева. М.: Юрист, 2006. 592 с.

32. Карасева М. В. Финансовое правоотношение. М.: Норма, 2001. 288 с.

33. Крылов О. М. Организация денежного обращения как функция государства: предмет, цели и методы // Налоги (журнал). 2013. № 4. С.5 - 9.

34. Лущаев Д. Ф. Частные квазиденьги (денежные суррогаты) в современной экономике: дис. ... канд.экон.наук: 08.00.01/ Лущаев Д. Ф. - Красноярск, 1999. 159 с.

35. О стратегии национальной безопасности: Указ Президента Российской Федерации от 12 мая 2009 г. № 537 (в ред. от 01 июля 2014 г. № 483) // Российская газета. 2009. № 88. 


\section{References (transliterated):}

1. Ob utverzhdenii Kontseptsii razvitiya rynka tsennykh bumag v Rossiiskoi Federatsii: Ukaz Prezidenta Rossiiskoi Federatsii ot 01 iyulya 1996 g. № 1008 (v red. ot 16 oktyabrya 2000 g. № 1756) // Rossiiskaya gazeta. 1996. № 125.

2. Chapchikov S. Yu. Konstitutsionnye garantii obespecheniya bezopasnosti obshchestva i gosudarstva // Konstitutsionnoe i munitsipal'noe pravo. 2009. № 17. S. 11 - 14.

3. Kleshchenko Yu. G., Savchenko M. M. Finansovyi kontrol' kak odin iz faktorov obespecheniya finansovoi bezopasnosti // Finansovoe pravo. 2009. № 5. S. 12 - 15.

4. Petrosyan 0. Sh. Finansovaya bezopasnost' Rossiiskogo gosudarstva v kontekste natsional'noi bezopasnosti // Gosudarstvennaya vlast' i mestnoe samoupravlenie. 2011. № 2. S. 32 - 34.

5. Nudel' S. L. Finansovaya bezopasnost' i osnovnye napravleniya ee obespecheniya // Finansovoe pravo. 2011 . № 8. S. 14 - 16.

6. Belikov E. G. Sotsial'nye aspekty funktsionirovaniya natsional'noi platezhnoi sistemy // Bankovskoe pravo. 2014 . № 4. S. $19-23$.

7. Kondrat E. N. Mezhdunarodnaya finansovaya bezopasnost': sovremennoe sostoyanie i rol' finansovogo kontrolya v ee obespechenii // Yuridicheskii mir. 2011. № 12. S. 32 - 34.

8. Morgun O. V., Shchedrin N. V. Osnovaniya i predely mer finansovoi bezopasnosti // Aktual'nye problemy rossiiskogo prava. 2013. №

9. S. 1165 - 1173. 9.Dolmatova N. G. Ponyatie finansovoi bezopasnosti gosudarstva kak ob"ekta pravovogo regulirovaniya // Finansovoe pravo. 2014. № 5. S. 33-37.

10. O denezhnoi sisteme Rossiiskoi Federatsii: Zakon Rossiiskoi Federatsii ot 25 sentyabrya 1992 g. № $3557-1$ (utratil silu v svyazi s prinyatiem Federal'nogo zakona ot 26 aprelya 1995 № 65-FZ) // Rossiiskaya gazeta. 1992. № 230.

11. Bel'skii K. S. K voprosu o ponyatii denezhnoi sistemy Rossiiskoi Federatsii // Finansovoe pravo. 2005. № 8. S.3 - 6.

12. Sattarova N. A. Den'gi kak ob"'ekt grazhdanskikh prav. - Kazan': Taglimat. 2006. 86 s.

13. Kucherov I. I. Zakonnoe platezhnoe sredstvo kak kategoriya finansovogo prava // Zhurnal rossiiskogo prava. 2014 . № 8. S. $38-47$.

14. Krylov O. M. Pravovoe regulirovanie denezhnogo obrashcheniya v Rossiiskoi Federatsii: monografiya /otv. red. S. V. Zapol'skii. - M.: KONTRAKT, 2014. 104 s.

15. Sokolova E. D. Pravovoe regulirovanie finansovoi deyatel'nosti gosudarstva i munitsipal'nykh obrazovanii. M.: Yurisprudentsiya, 2009.264 s.

16. Krylov O. M. Diskussionnye voprosy finansovo-pravovogo regulirovaniya denezhnogo obrashcheniya $\mathrm{v}$ Rossiiskoi Federatsii // Finansovoe pravo. 2014. № 8. S.3 - 10.

17. Zapol'skii S. V. Teoriya finansovogo prava: Nauchnye ocherki. - M.: GOU VPO «Rossiiskaya akademiya pravosudiya», $2010.371 \mathrm{~s}$.

18. Khudyakov A. I. Finansovoe pravo Respubliki Kazakhstan. Obshchaya chast'. Almaty: TO0 «Baspa», 2001.272 s.

19. Ashmarina E. M. Nekotorye aspekty rasshireniya predmeta finansovogo prava v Rossiiskoi Federatsii: problemy i perspektivy: monografiya. M.: Poligraf OPT, 2004. 253 s.

20. Gurvich M.A. Sovetskoe finansovoe pravo. M.: Gosyurizdat, 1952. 324 s.

21. Rovinskii E. A. Osnovnye voprosy teorii sovetskogo finansovogo prava. M.: Gosyurizdat, 1960.193 s.

22. Kucheryavenko N. P. K voprosu o soglasovanii norm, reguliruyushchikh finansovuyu deyatel'nost' // Finansovoe pravo. 2004. № 1. S. 10 - 13.

23. Finansovoe pravo: uchebnoe posobie / otv. red. I. V. Rukavishnikova. M.: Norma, 2007. $512 \mathrm{s.}$

24. Finansovoe pravo: Uchebnik / otv. red. N. I. Khimicheva. M.: Norma, 2011. 768 s.

25. Finansovoe pravo: uchebnik / pod red. E. Yu. Grachevoi. M., 2012. 789 s.

26. Krokhina Yu. A. Finansovoe pravo Rossii: uchebnik. M.: Norma, 2011. $720 \mathrm{s.}$

27. Arzumanova L. L. Pravo denezhnogo obrashcheniya kak podotrasl' finansovogo prava Rossiiskoi Federatsii: avtoref. dis.... na soisk. uchen. st. d-ra yurid. nauk. Spetsial'nost' 12.00.04-finansovoe pravo, nalogovoe pravo, byudzhetnoe pravo / L. L. Arzumanova ; nauch. kons. E. Yu. Gracheva.-M., 2014.-44 s.

28. O Tsentral'nom banke Rossiiskoi Federatsii (Banke Rossii): Federal'nyi zakon ot 10 iyulya 2002 g. № 86-FZ (v red. ot 29 dekabrya 2014 g. № 484-FZ) // Rossiiskaya gazeta. 2002. № 127.

29. Teoriya gosudarstva i prava: uchebnik / pod red. R. A. Romashova. SPb.: Izdatel'stvo R. Aslanova «Yuridicheskii tsentr Press», 2005. 630 s.

30. Teoriya gosudarstva i prava: Kurs lektsii / Pod red. N. I. Matuzova i A. V. Mal'ko. - M.: Yurist", 2006. 776 s.

31. Teoriya gosudarstva i prava: uchebnik / pod red. V.K. Babaeva. M.: Yurist, 2006. 592 s.

32. Karaseva M. V. Finansovoe pravootnoshenie. M.: Norma, 2001. 288 s.

33. Krylov O. M. Organizatsiya denezhnogo obrashcheniya kak funktsiya gosudarstva: predmet, tseli i metody // Nalogi (zhurnal). 2013. № 4. S.5 - 9.

34. Lushchaev D. F. Chastnye kvaziden'gi (denezhnye surrogaty) v sovremennoi ekonomike: dis. ... kand.ekon.nauk: 08.00.01/ Lushchaev D. F. - Krasnoyarsk, 1999.159 s.

35. O strategii natsional'noi bezopasnosti: Ukaz Prezidenta Rossiiskoi Federatsii ot 12 maya 2009 g. № 537 (v red. ot 01 iyulya 2014 g. № 483) // Rossiiskaya gazeta. 2009. № 88. 